\title{
D-Shaped Polarization Maintaining Fiber Sensor for Strain and Temperature Monitoring
}

\author{
Hummad Habib Qazi ${ }^{1}$, Abu Bakar Mohammad ${ }^{1, *}$, Harith Ahmad ${ }^{2}$ and Mohd Zamani Zulkifli ${ }^{2}$ \\ 1 Faculty of Electrical Engineering, Universiti Teknologi Malaysia, UTM, Skudai, 81310 Johor, Malaysia; \\ hqhummad3@live.utm.my \\ 2 Photonics Research Centre, University of Malaya, 50603 Kuala Lumpur, Malaysia; \\ harith@um.edu.my (H.A.); mohdzamani@um.edu.my (M.Z.Z.) \\ * Correspondence: bakar@fke.utm.my; Tel.: +60-755-35375
}

Academic Editor: Vittorio M. N. Passaro

Received: 31 May 2016; Accepted: 25 August 2016; Published: 15 September 2016

\begin{abstract}
A D-shaped polarization-maintaining fiber (PMF) as fiber optic sensor for the simultaneous monitoring of strain and the surrounding temperature is presented. A mechanical end and edge polishing system with aluminum oxide polishing film is utilized to perform sequential polishing on one side (lengthwise) of the PMF in order to fabricate a D-shaped cross-section. Experimental results show that the proposed sensor has high sensitivity of $46 \mathrm{pm} / \mu \varepsilon$ and $130 \mathrm{pm} /{ }^{\circ} \mathrm{C}$ for strain and temperature, respectively, which is significantly higher than other recently reported work (mainly from 2013) related to fiber optic sensors. The easy fabrication method, high sensitivity, and good linearity make this sensing device applicable in various applications such as health monitoring and spatial analysis of engineering structures.
\end{abstract}

Keywords: fiber optic sensor; polarization-maintaining fiber; fiber loop mirror; strain sensor; temperature sensor; structural health monitoring

\section{Introduction}

Fiber optic sensor (FOS) technologies have gained wide interest for sensing applications during the recent decades due to comparative advantages over other conventional sensor technologies. These advantages include rapid responsiveness, compact size, safety, stability, flexibility, capability for remote monitoring and suitability to perform in harsh environments. FOS are designed to collect information via fiber optics, based on the fact that alterations in a specific physical property of a medium being sensed will cause a predictable change in the light transmission characteristics of the fiber. More recently, meaningful efforts have been made to develop an optical fiber-based sensing system for the simultaneous monitoring of multi-parameters, such as strain, temperature, vibration, refractive index and others [1-7]. In general, a fiber optic sensing system for simultaneous monitoring of multi-parameters requires a complex sensing head with multiple detection features, and each of them should exhibit a unique response to the external parameter to be measured [8]. It is not to say that all of these and other reported works are not capable of monitoring external parameters precisely; every contemporary sensing method possesses particular advantages and disadvantages. For example, Song et al. report a fiber Bragg grating (FBG)-based FOS for the simultaneous monitoring of strain and temperature sensing applications [9]. However, it has been observed that in the reported sensing device, the location of the FBG and the sensing element of the sensor was not same, which may cause the production of measurement errors in the sensing system.

In principle, FOS rely on the fact that alterations in a specific physical property of a medium being sensed would cause a predictable change in the light transmission characteristics of the fiber [10-12]. To make an optical fiber sensitive to the external environment, the waveguide property is altered by 
some appropriate technique (generally by removing the cladding). Rather than removing the entire cladding of an optical fiber for a certain length, which causes the reduction of the strength, sustainability and durability, an alternative method is to use a D-shaped optical fiber sensor, which is comparatively strong and stable without compromising the sensitivity of the sensing device $[13,14]$. D-shaped optical fibers can be fabricated by removing a portion of cladding (lengthwise) of the optical fiber until the core of the fiber, and hence at a strong interaction between the evanescent field of the light signal and the external environment can occur at the polished surface [15]. Producing a D-sector on optical fibers through polishing techniques is appropriate [16]. Conventionally, an optical fiber is glued by epoxy in a cut curved V-shaped groove while its cladding is polished away over a limited interaction length of several millimeters. Depending upon the diameters of both the core and cladding, different sizes of V-shaped grooves have to be prepared precisely in advance by complicated techniques to produce a D-shaped sensor with desired dimensions [17]. Furthermore, this technique may suffer from fiber deformations such as scratches, cracks, or broken regions if the polishing protocol is not proper for the materials of the optical fiber and the surroundings. Thus, the polishing process needs very careful attention during the application. Beside all of these, the major drawback of the conventional method of the polishing technique is setting the fibers permanently into the V-shaped groove, which challenges the main advantages offered by optical fiber sensors, such as small size, easily access to hard-to-access areas, and of course the mobility of the sensing device. This makes the device less suitable from a practical point of view.

Alternatively, a D-sector on an optical fiber can be produced by using a $\mathrm{CO}_{2}$ laser or femtosecond laser machining [18-21]. In general, plastic cladding can easily be stripped with a desired dimension to expose the fiber core by $\mathrm{CO}_{2}$ laser machining [22,23]. However, this technique is not useful to alter the silica-based optical fibers. Recently, Chen et al. introduced a new type of multi-D-shaped optical fiber sensor to monitor the refractive index of liquids [20]. In this work, the femtosecond laser pulse was used to fabricate a number of D-sectors on multimode optical fibers. However, the shorter length $(1 \mathrm{~mm})$ along the axis of the optical fiber makes this device less suitable for fiber optic-based sensing applications. Table 1 summarizes the currently reported D-shaped optical fiber sensors in the literature.

Table 1. Summary of D-shaped optical fiber sensors.

\begin{tabular}{|c|c|c|c|c|c|}
\hline No. & Type of Fiber & Polishing Technique & Dimension $(h \times w \times l) * 1$ & Application & Ref \\
\hline 1 & Multimode optical fiber & $\begin{array}{l}\text { Femtosecond laser } \\
\text { micromachining }\end{array}$ & $100 \mu \mathrm{m} \times 250 \mu \mathrm{m} \times 1 \mathrm{~mm}$ & $\begin{array}{l}\text { Liquid refractive } \\
\text { index measurements }\end{array}$ & {$[20]$} \\
\hline 2 & Polarization-maintaining fiber & $\begin{array}{l}\text { Hydrofluoric } \\
\text { acid etching }\end{array}$ & - & $\begin{array}{l}\text { Liquid refractive } \\
\text { index measurements }\end{array}$ & {$[24]$} \\
\hline 3 & Plastic Optical Fiber & $\begin{array}{c}\text { Rotating } \\
\text { grinding wheel }\end{array}$ & $10 \mathrm{~mm}$ (length) & $\begin{array}{l}\text { Liquid refractive } \\
\text { index measurements }\end{array}$ & [25] \\
\hline 4 & Single-mode optical fiber & $\begin{array}{l}\text { Femtosecond laser } \\
\text { micromachining }\end{array}$ & $60 \mu \mathrm{m} \times 75 \mu \mathrm{m}(\mathrm{h} \times 1)$ & $\begin{array}{l}\text { Liquid refractive } \\
\text { index measurements }\end{array}$ & [26] \\
\hline 5 & Multimode optical fiber & $\begin{array}{c}\text { Femtosecond laser } \\
\text { micromachining }\end{array}$ & $100 \mu \mathrm{m} \times 1 \mathrm{~mm}(\mathrm{~h} \times 1)$ & $\begin{array}{l}\text { Liquid refractive } \\
\text { index measurements }\end{array}$ & [21] \\
\hline 6 & Single-mode optical fiber & $\begin{array}{c}\text { Mechanical } \\
\text { wheel lapping }\end{array}$ & 4 mm (length) & $\begin{array}{l}\text { Strain and } \\
\text { Temperature }\end{array}$ & {$[27]$} \\
\hline
\end{tabular}

Furthermore, in optical fiber sensing applications where the external parameters do not have significant effects on the light transmission characteristics, i.e., attenuation, reflection, etc., and the fiber optic sensing system is unable to perform well, it is possible that the polarization of the optical wave may have a significant effect on the sensing system behavior and monitoring of the wavelength shift may give some meaningful information [28]. In such applications, utilization of single-mode fibers may suffer from unpredictable phase shift and/or time-varying polarization changes because 
of various external parameters and hence may cause errors in the measurements. The remedy of this problem is to introduce a polarization-maintaining fiber (PMF) in the sensing system [29].

To improve the above shortcomings, this paper presents a D-shaped PMF loop mirror-based FOS for the simultaneous monitoring of strain and the surrounding temperature. A mechanical end and edge polishing system with aluminum oxide polishing film was utilized to perform sequential polishing on one side (lengthwise) of the PMF in order to obtain a D-shaped cross-section in the laboratory environment. Adjusting the specific mechanical parameters allowed the control of the D-shaped zone. To meet the accuracy and repeatability requirements, optical power loss was monitored during the entire polishing process in situ and in real time. The performance of the D-shaped PMF sensor has been analyzed to monitor the applied strain and the variation in the surrounding temperature. Experimental results show that the proposed sensor has high sensitivity of $0.046 \mathrm{~nm} / \mu \varepsilon$ and $0.13 \mathrm{~nm} /{ }^{\circ} \mathrm{C}$ for strain and temperature, respectively. The sensor has a linear response over a measurable range of 0 to $50 \mu \varepsilon$ for strain and $30^{\circ} \mathrm{C}$ to $80^{\circ} \mathrm{C}$ for temperature, respectively.

\section{Fabrication Process}

In this work, a new polishing technique is employed to produce D-sector on a PMF (PANDA, 1027-C, Yangtze Optical Fibre and Cable Joint Stock Limited Company (YOFC), Wuhan, China). An ULTRAPOL end and edge polishing system (model 3690.1) is the principal equipment utilized for the fabrication of a D-sector on the PMF. This particular polishing system is designed to polish ends and edges of waveguides and cannot be used to polish along the length of an optical fiber without mechanical alteration. The lengthwise polishing of PMF, to fabricate a D-sector on it, using this particular polishing system is possible after installing a custom die made by a cast acrylic sheet. The major advantages of using this polishing system are: it is comparatively simple, fast, safe, stable, and straightforward. Moreover, it allows a certain amount of flexibility in terms of the shape of the exposed area and also the thickness of the polished core.

A conceptual illustration of the polishing system is given in Figure 1, where arrowed lines indicate the pathway of the optical fiber in the die and $\theta$ is the angle made by both ends of the optical fiber with the polishing end of the die. The rectangle shape with dashed outlines in the figure represents the acrylic sheet, while the round shape indicates the polishing film under the die. By monitoring the transmitted optical power loss and microscopic measurements of the D-sector during the polishing process, the D-sector is fabricated on the PMF with specific intended dimensions.

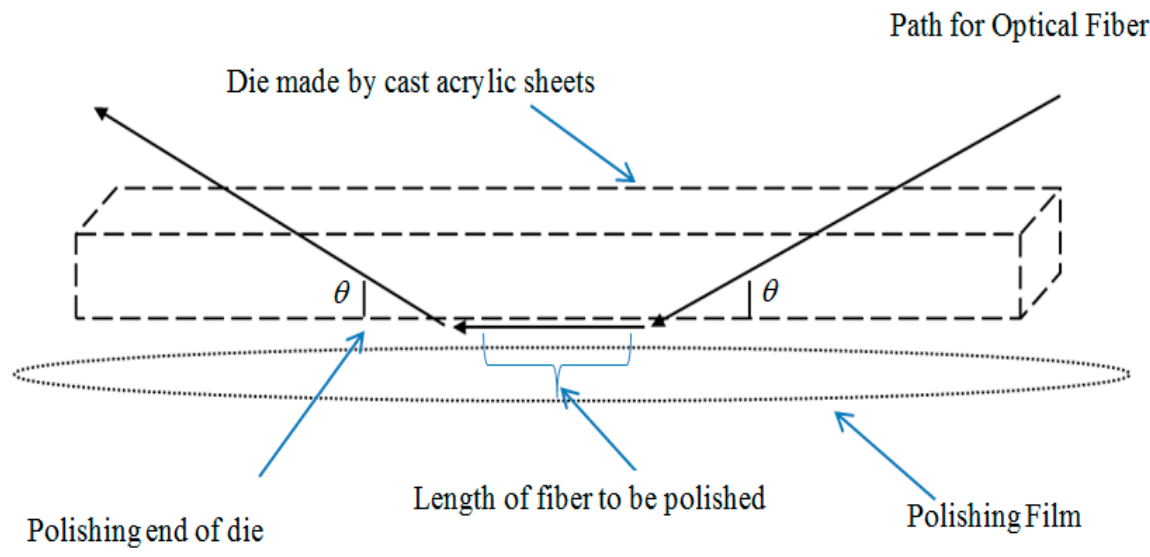

Figure 1. Conceptual illustration of the polishing system.

A cast acrylic sheet was used to build a base of $5 \times 1 \times 0.5(1 \times \mathrm{w} \times \mathrm{h}) \mathrm{cm}^{3}$ dimensions for the polishing die. A holding strip in the die center allowed for a secure attachment of the die to the holder of the polishing system. Two tiny holes of $1 \mathrm{~mm}$ diameter are made in a vertical cross-section such that the distance between these two holes at the polishing surface was equal to the intended length 
for polishing. The angle $\theta$ between the polishing surface and the tiny holes was varied from $20^{\circ}$ to $45^{\circ}$ in order to determine the optimum efficiency for polishing. This polishing system can polish a waveguide surface maximum up to $8 \mathrm{in}$. When $\theta$ is less than $20^{\circ}$, the length of the polishing surface unnecessarily increases. Furthermore, fixing the die at the center of the polishing film causes it to crash the fiber all of sudden, because of the rotatory motion of polishing film under the polishing surface. On the other hand, through experiment it is found that $\theta$ greater than $35^{\circ}$ causes an increase in the risk of fiber breakage during the polishing process and the consequent cost escalation of a single run. Experimental results from varying the angle indicate that $\theta \approx 30^{\circ}$ was the optimum angle for holes.

An optical fiber was threaded through both holes and tightly fastened with cellophane tape to the upper surface of the die to avoid misplacement during the polishing process. The die holding strip was next fixed securely in the holding arm of the polishing system. Appropriate polishing film was then applied at the polishing plate, the number of rotations per minute was set, and the timer was configured for an appropriate duration. The polishing system was subsequently engaged to start polishing one lengthwise side of the optical fiber so as to gradually fabricate a D-sector on the optical fiber.

Polishing on the PMF was performed using the polishing system with a $30 \mu \mathrm{m}$ layer of aluminum oxide polishing film along with 90 polishing plate rotations per minute. To meet the accuracy and repeatability requirements, optical power loss was monitored during the entire polishing process in situ and in real time. This made it possible to fabricate a D-sector on optical fiber with a desired height more precisely and accurately. For the sake of validation, precision and repeatability of the proposed polishing technique, three sets of single-mode optical fibers (each set contains five PMFs) were polished until transmission power loss was reached at $-3( \pm 0.04),-6( \pm 0.04)$ and $-9( \pm 0.04) \mathrm{dB}$, respectively.

Figure 2 presents the power transmission loss of each of the polished optical fibers during and after the polishing process (while the optical fiber was unplugged from the polishing system). Figure 3 presents the average transmission power loss as a function of the residual cladding on the polished surface of the D-sector, during and after the polishing process. The conceptual illustration of the D-sector on the PMF is presented in Figure 4.

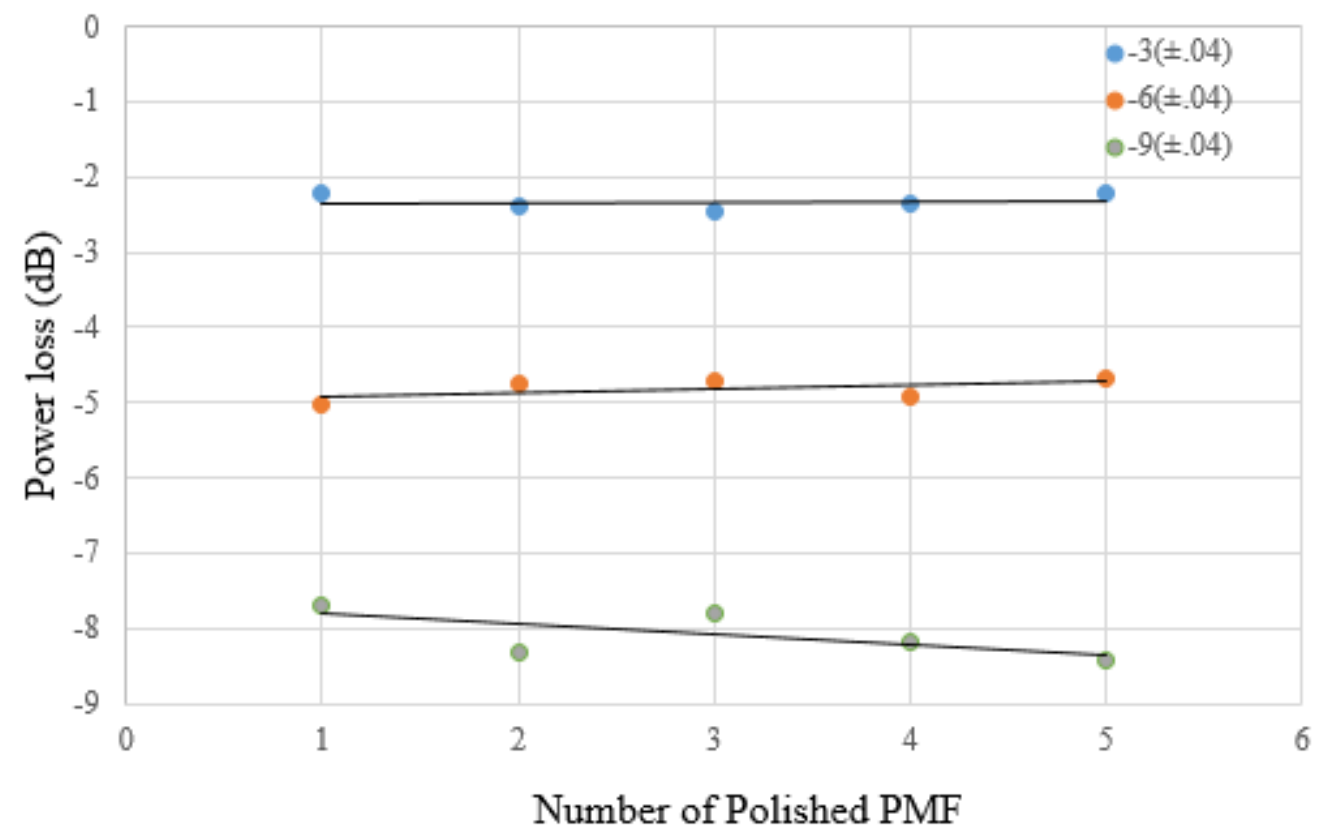

Figure 2. Power loss of each polished PMF (during and after the polishing process), three sets of PMFs (each set contains five optical fibers) were polished until transmission power loss was reached at $-3( \pm 0.04),-6( \pm 0.04)$ and $-9( \pm 0.04) \mathrm{dB}$, respectively. 


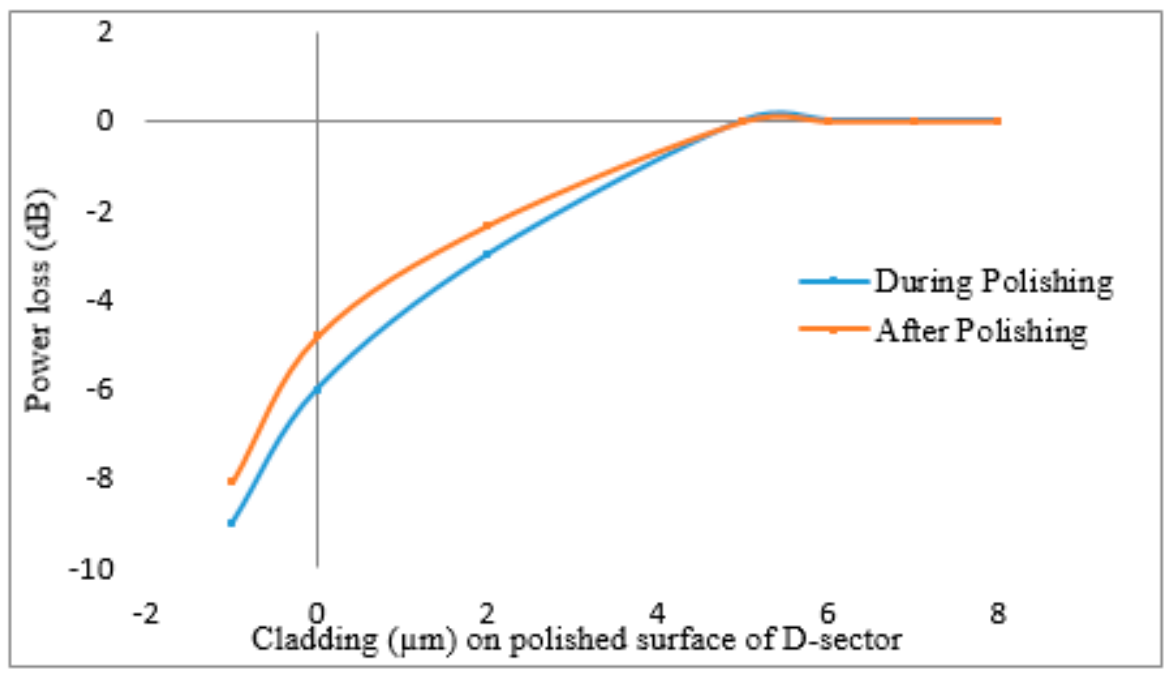

Figure 3. Average transmission power loss as a function of residual cladding on polished surface.

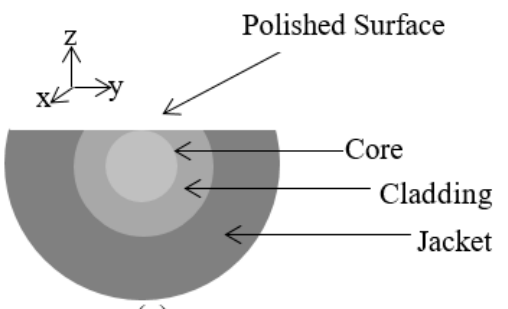

(a)

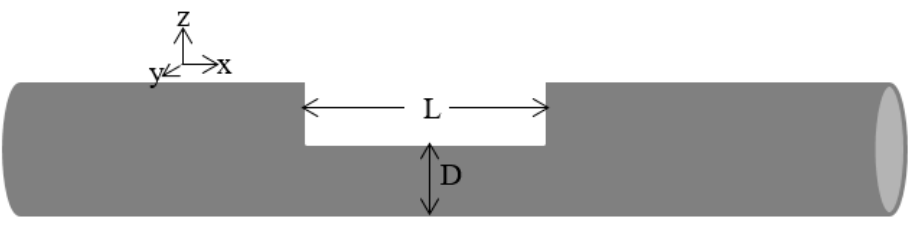

(b)

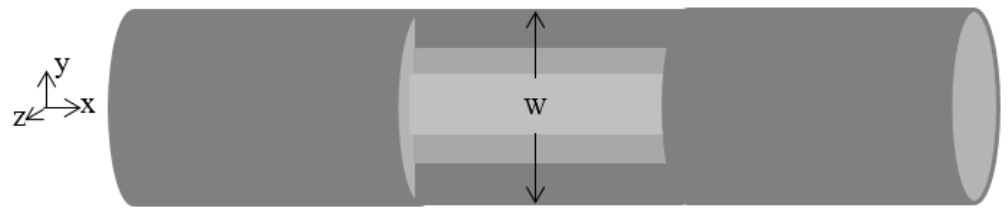

(c)

Figure 4. Conceptual illustration of D-sector on PMF: (a) Cross-sectional view at $Y$-Z plane, (b) cross-sectional view at $X-Z$ plane and (c) cross-sectional view at $Y$-X plane; $L$ is the length of the polished surface, $\mathrm{D}$ is the diameter of the $\mathrm{D}$-sector and $\mathrm{W}$ is the width of the $\mathrm{D}$-sector.

\section{Experimental Setup and Sensing Principle}

Refer to Figure 4, where $\mathrm{L}$ is the length, $\mathrm{D}$ is the diameter and $\mathrm{W}$ is the width of the $\mathrm{D}$-sector. In this work a D-shaped PMF sensor (with dimensions of $10 \mathrm{~mm} \times 205 \mu \mathrm{m} \times 195 \mu \mathrm{m}(\mathrm{L} \times \mathrm{D} \times \mathrm{W})$ ) is used to analyze the sensor's performance to monitor the variation in the applied stress and the surrounding temperature. Before the experiment is conducted to analyze the sensor from a practical point of view, a power transmission loss of $2.46 \mathrm{~dB}$ is observed in the sensing device. A schematic diagram of the experimental setup for the proposed sensor is presented in Figure 5. In this work, an amplified spontaneous emission (ASE) source with a wavelength range of 1450-1650 nm is used as the light source. The light source is connected to the input port of the fiber loop mirror. The fiber loop mirror is constructed by splicing a D-shaped PMF sensor along with a polarization controller (PC) to a $2 \times 23-\mathrm{dB}$ coupler. The purpose of introducing PC in the sensing system is only to enhance the fringe visibility of the interference pattern. An optical spectrum analyzer (OSA, Yogogawa AQ6370C, Tokyo, Japan) connected at the output port of the fiber loop mirror, to complete the experimental set-up. The input light signal from the ASE is equally split and transmitted in both directions, clockwise and counter-clockwise in the fiber loop mirror (FLM). 


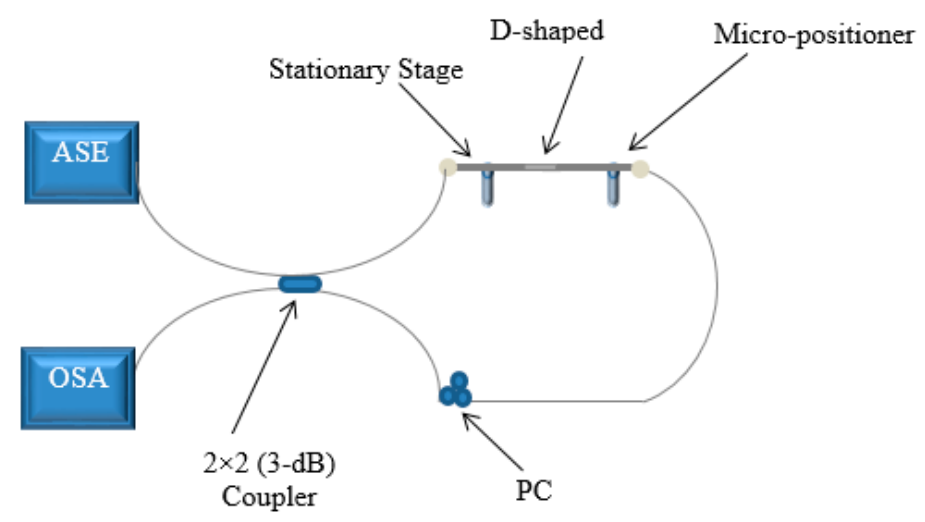

Figure 5. Schematic diagram of experimental setup of proposed strain and temperature sensor.

Due to the birefringence property of PMF, a relative phase difference is produced in the counter-propagating light beams. Interference is generated when both of the light beams are recombined at the $3 \mathrm{~dB}$ coupler. The optical transmission intensity $I_{T}$ in terms of phase difference can be defined as [24]:

$$
I_{T}=\frac{I_{o}(1-\cos \varphi)}{2}
$$

and

$$
\varphi=\frac{2 \pi L B}{\lambda}
$$

where $\varphi$ is the phase difference, $\lambda$ is the wavelength of interest for the light source, $I$ is the intensity of the input light, $\mathrm{L}$ is the length of the PMF and $B=n_{s}-n_{f}$ is the birefringence index of the PMF. Further, $n_{s}$ and $n_{f}$ are the effective refractive indices of the slow and fast axis of the PMF, respectively. Also, the resonant dip wavelength satisfies the equation $\varphi=2 k \pi$ and $k$ is a random integer. So, the resonant dip wavelength can be expressed as:

$$
\lambda=\frac{L B}{k}
$$

The changing of the external strain or temperature can cause a change of the length $L$ and the birefringence $B$ of the PMF. This characteristic leads to a wavelength shift of the interference spectra. The relationship between the wavelength shifts $\Delta \lambda$ and $\Delta B$ and $\Delta L$ (as strain $\varepsilon=\Delta L / L$ ) can be expressed as:

$$
\Delta \lambda=\frac{(L \Delta B+B \Delta L)}{k}=\frac{L}{k}\left(P_{t} \Delta T+B \varepsilon\right)
$$

where $P_{t}$ is the thermo-optic constant of PMF, $\Delta L$ is the change in length of PMF caused by the applied strain and $\Delta B$ is the birefringence change caused by the variation of the surrounding temperature, while $\Delta T$ is the variation in the surrounding temperature [30].

It is clear that any change in the surrounding medium directly affects the propagation constants or the length of the D-type PMF loop mirror, which can be quantified either in terms of power loss or the spectral location of the peak/dip. In this work, two consecutive resonant dip wavelengths $\left(\lambda_{1}\right.$ and $\left.\lambda_{2}\right)$ are chosen as measurement parameters for simultaneous monitoring of the strain and temperature.

\section{Results and Discussion}

The performance of the proposed D-type PMF loop mirror sensor has been characterized for strain and temperature. In this work, strain and temperature are applied using a movable stage and a heating plate, respectively. Figure 6 presents the spectral variation of the D-type PMF loop mirror as a function of the strain, ranging from zero micro-strain $(\mu \varepsilon)$ to $50 \mu \varepsilon$. Two consecutive minima fringes at $\lambda_{1}=1536.6 \mathrm{~nm}$ and $\lambda_{2}=1546.7 \mathrm{~nm}$ were chosen to measure the spectral strain variation as a function 
of the strain. The relationships between the strain and the wavelength variation for both $\lambda_{1}$ and $\lambda_{2}$ are presented in Figure 7. A linear fit with a slope of $0.046 \mathrm{~nm} / \mu \varepsilon$ and $0.047 \mathrm{~nm} / \mu \varepsilon$ is obtained for both $\lambda_{1}$ and $\lambda_{2}$, respectively. To monitor spectral variation as a function of the temperature, two consecutive minima fringes at $\lambda_{1}=1536.58 \mathrm{~nm}$ and $\lambda_{2}=1551.65 \mathrm{~nm}$ at $30{ }^{\circ} \mathrm{C}$ were chosen as a reference. Figure 8 presents the relationship between the wavelength variation and the temperature for both of the wavelengths $\lambda_{1}$ and $\lambda_{2}$. The temperature sensitivity for the proposed sensor corresponding to $\lambda_{1}$ and $\lambda_{2}$ is $0.13 \mathrm{~nm} /{ }^{\circ} \mathrm{C}$ and $0.14 \mathrm{~nm} /{ }^{\circ} \mathrm{C}$, respectively. The fitting linearity coefficients $\mathrm{R}^{2}$ for the applied strain, for both $\lambda_{1}$ and $\lambda_{2}$, are 0.977 and 0.973 , respectively, as presented in Figure 7 . The linearity coefficient changes in the surrounding temperature are 0.963 and 0.961 for both $\lambda_{1}$ and $\lambda_{2}$, respectively. The sensitivity coefficient of the reported sensor for both strain and temperature is given in Table 2.

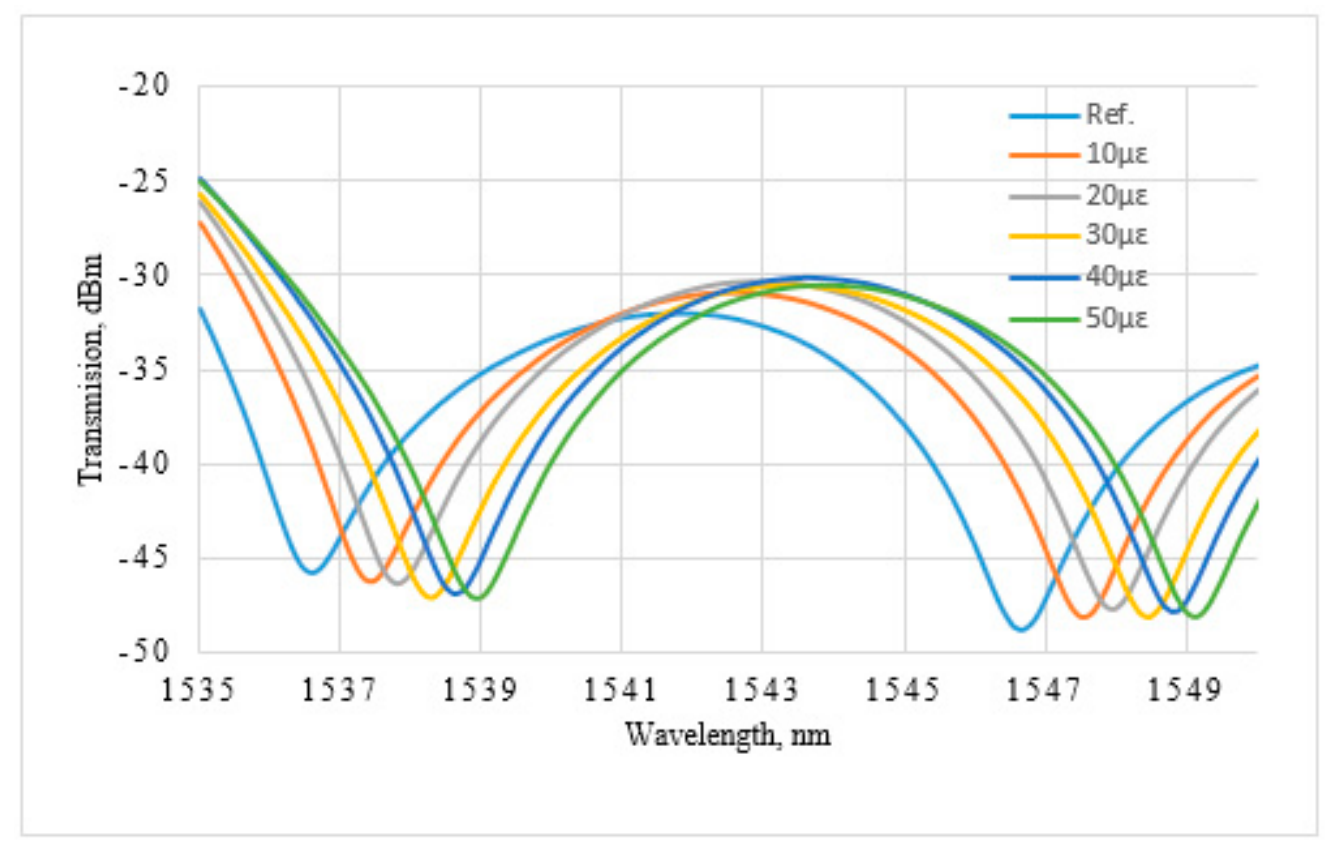

Figure 6. Spectral variation of D-type PMF loop mirror as a function of strain.

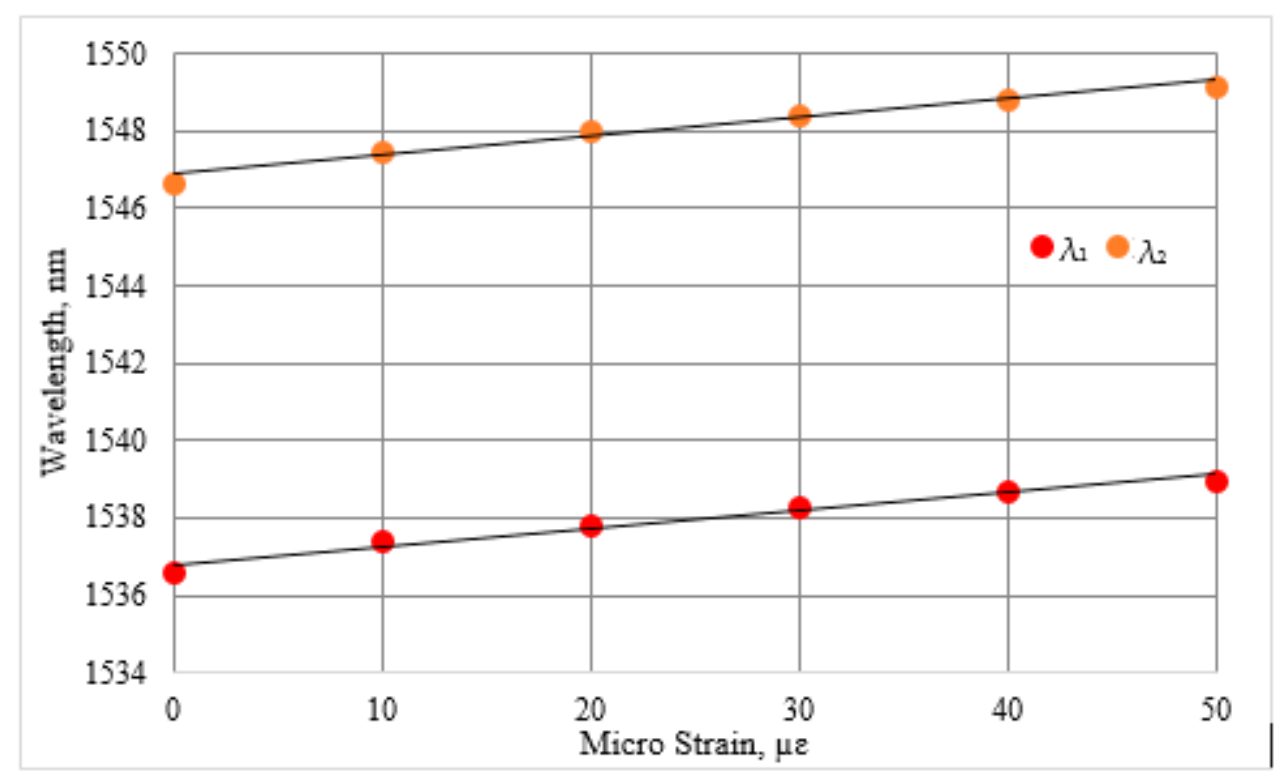

Figure 7. Wavelength shift of $\lambda_{1}$ and $\lambda_{2}$ as a function of strain. 


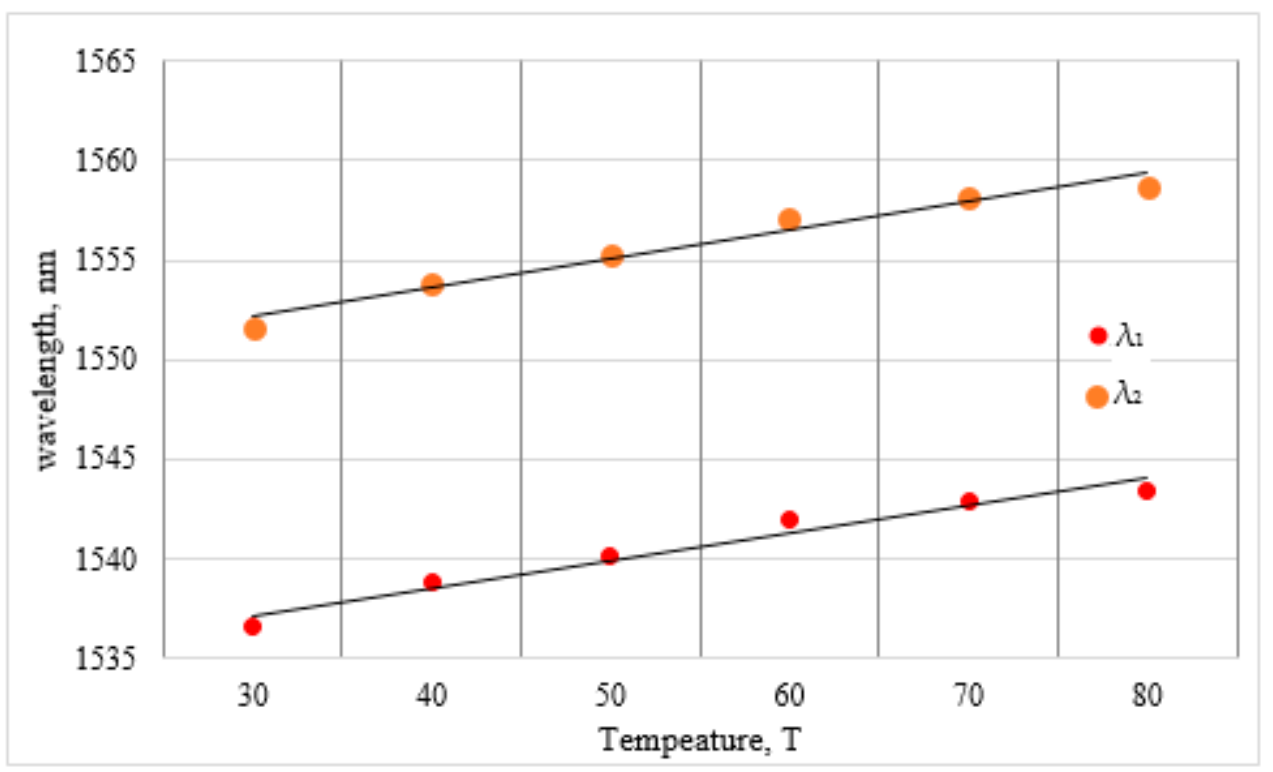

Figure 8. Wavelength shift of $\lambda_{1}$ and $\lambda_{2}$ as a function of temperature.

Table 2. Sensitivity coefficient of D-shaped PMF loop mirror for both strain and temperature.

\begin{tabular}{ccc}
\hline & $\mathrm{K} \varepsilon(\mathrm{nm} / \mu \varepsilon)$ & $\mathrm{K}_{\mathrm{T}}\left(\mathrm{nm} /{ }^{\circ} \mathrm{C}\right)$ \\
\hline First Minima $\left(\lambda_{1}\right)$ & 0.046 & 0.13 \\
Second Minima $\left(\lambda_{2}\right)$ & 0.047 & 0.14 \\
\hline
\end{tabular}

From the aforementioned characterization of the D-shaped PMF loop mirror, it is clear that the D-type PMF sensor has a linear and independent response for strain and temperature.

Therefore, it is possible to write two independent equations allowing explicit solutions for the actual value of each parameter, even in the situation when both parameters are changing. For this purpose, the matrix method can be used to determine the variation in both of the parameters for which the sensor is sensitive to [31]. Hence, the change in strain and surrounding temperature can be obtained simultaneously by using following matrix equation:

$$
\left[\begin{array}{c}
\Delta T \\
\Delta \varepsilon
\end{array}\right]=\frac{1}{D}\left[\begin{array}{cc}
K_{\varepsilon 2} & -K_{\varepsilon 1} \\
-K_{T 2} & K_{T 1}
\end{array}\right]\left[\begin{array}{l}
\Delta \lambda_{1} \\
\Delta \lambda_{2}
\end{array}\right]
$$

where $D=K_{T 1} K_{\varepsilon 2}-K_{\varepsilon 1} K_{T 2}$, and the strain and temperature coefficients are obtained by fitting the experimental data using the linear regression as presented in Figures 7 and 8. The above matrix system becomes:

$$
\left[\begin{array}{c}
\Delta T \\
\Delta \varepsilon
\end{array}\right]=-\frac{1}{0.003}\left[\begin{array}{cc}
0.047 & -0.046 \\
-0.14 & 0.13
\end{array}\right]\left[\begin{array}{l}
\Delta \lambda_{1} \\
\Delta \lambda_{2}
\end{array}\right]
$$

The performance of the sensor has been analyzed for monitoring the variation in the strain and surrounding temperature over a range of $50 \mu \varepsilon$ and $50{ }^{\circ} \mathrm{C}$, respectively. The maximum error was found to be $\pm 0.003 \mathrm{~nm} / \mu \varepsilon$ and $\pm 0.01 \mathrm{~nm} /{ }^{\circ} \mathrm{C}$ for the strain and temperature correspondingly, which is negligible in practical applications.

\section{Comparison of this Sensor with Other FOS for Strain and/or Temperature}

Despite of all the progress in the field of fiber optic sensing techniques, to differentiate and analyze the simultaneous effects of various external parameters, such as strain, temperature, refractive index, pressure, etc., on fiber optic sensing systems is critical to the large-scale success of any fiber sensing 
technique. This is not only because the cross-sensitivity is a key issue for the practical applications of fiber optic sensors, but multi-parameter sensors can also reduce the complexity of the sensing systems [32]. Recently, Changyu Shen et al. presented a low-birefringence PMF-FLM interferometer temperature-insensitive strain sensor [30]. The proposed strain sensor was formed by inserting two equal sections of low-birefringence PMFs into a FLM. Two equal-length sections of PMFs were separated by a single-mode fiber (SMF). One of the PMFs was used as the sensing element, and the other one was used as the temperature compensation element. The sensitivity of the proposed sensor was $3.5 \mathrm{pm} / \mu \varepsilon$. In another work, a slightly tapered optical fiber with an inner air cavity is proposed and demonstrated for simultaneous strain and temperature measurements [33]. The sensing device was fabricated by using femtosecond laser micromachining together with fusion splicing techniques, followed by a short-duration tapering process. The reported sensor exhibited sensitivity of $-16.12 \mathrm{pm} / \mu \varepsilon$ and $85 \mathrm{pm} /{ }^{\circ} \mathrm{C}$ for both strain and temperature, respectively. Table 3 presents a comparative study in terms of sensitivity between the sensor presented in this work and more recent FOS works (mostly from 2013 to onward) for strain and/or temperature sensing applications. It is clear from the table that the reported sensor possesses significantly high sensitivity toward strain and temperature compared to its competitors. Moreover, a simple, rapid, safer and more stable fabrication method to fabricate this sensor and a straightforward monitoring procedure make this device more suitable from a practical point of view.

Table 3. Comparison of the sensitivity of the sensor presented in this work with other recently reported (mainly from 2013) FOSs for strain and temperature.

\begin{tabular}{|c|c|c|c|c|c|}
\hline \multirow{2}{*}{ No } & \multirow{2}{*}{$\begin{array}{l}\text { Sensing Principle/ } \\
\text { Type of Fiber }\end{array}$} & \multirow{2}{*}{$\begin{array}{c}\text { Sensing } \\
\text { Application }\end{array}$} & \multicolumn{2}{|c|}{ Sensitivity } & \multirow{2}{*}{ Ref. } \\
\hline & & & Strain $\mathrm{pm} / \mu \varepsilon$ & Temperature $\mathrm{pm} /{ }^{\circ} \mathrm{C}$ & \\
\hline 1 & $\begin{array}{l}\text { Hybrid optical fiber structure FLM-long period } \\
\text { fiber gratings (LPFGs)-few mode fiber (FMF) }\end{array}$ & $\begin{array}{l}\text { Strain and } \\
\text { Temperature }\end{array}$ & -2.9 & -17.6 & {$[34]$} \\
\hline 2 & FLM-low-birefringence PMF & Strain & 3.5 & - & {$[30]$} \\
\hline 3 & $\begin{array}{l}\text { No-core fiber (NCF)-fiber Bragg grating } \\
\text { (FBG)-SMF }\end{array}$ & $\begin{array}{l}\text { Strain and } \\
\text { Temperature }\end{array}$ & 1.19 & 12.8 & [35] \\
\hline 4 & $\begin{array}{l}\text { Erbium-doped fiber (EDF)-FBG-Mach-Zehnder } \\
\text { interferometer (MZI) }\end{array}$ & Temperature & - & 18.8 & {$[36]$} \\
\hline 5 & Combined polymer and silica-based FBG & $\begin{array}{l}\text { Strain and } \\
\text { Temperature }\end{array}$ & 1.48 & - & [37] \\
\hline 6 & $\begin{array}{l}\text { Slightly tapered optical fiber with an inner } \\
\text { air cavity }\end{array}$ & $\begin{array}{l}\text { Strain and } \\
\text { Temperature }\end{array}$ & -16.12 & 85.95 & {$[38]$} \\
\hline 7 & Dual gratings in one fiber & $\begin{array}{l}\text { Strain and } \\
\text { Temperature }\end{array}$ & 2.57 & 8.5 & [33] \\
\hline 8 & PM-photonic crystal fiber (PM-PCF) & Strain & 1.3 & 0.3 & [39] \\
\hline 9 & PM-PCF & Strain & 2.04 & - & {$[40]$} \\
\hline 10 & PM-FLM & $\begin{array}{l}\text { Strain and } \\
\text { vibration }\end{array}$ & 1.09 & - & [3] \\
\hline 11 & D-shaped PM-FLM & $\begin{array}{l}\text { Strain and } \\
\text { Temperature }\end{array}$ & 46 & 130 & $\begin{array}{l}\text { This } \\
\text { work }\end{array}$ \\
\hline
\end{tabular}

\section{Conclusions}

A compact size D-shaped PMF loop mirror sensor for the simultaneous monitoring of strain and temperature has been presented and characterized successfully. A mechanical end and edge polishing system with aluminum oxide polishing film was utilized to perform sequential polishing on one side (lengthwise) of the PMF in order to obtain a D-shaped cross-section in the laboratory environment. Adjusting specific mechanical parameters allowed the control of the D-shaped zone. The major advantages of using said polishing system are that it is comparatively simple, fast, safe, stable, and straightforward. Moreover, it allows a certain amount of flexibility in terms of the shape of the 
exposed area and also the thickness of the core. To meet the accuracy and repeatability requirements, optical power loss was monitored during the entire polishing process in situ and in real time. Experimental results show that the proposed sensor has high sensitivity of $46 \mathrm{pm} / \mu \varepsilon$ and $130 \mathrm{pm} /{ }^{\circ} \mathrm{C}$ for variation in the strain and surrounding temperature, respectively, which is quite high compared to other recently reported (mainly from 2013) related fiber optic sensors. These values were found to have a linear response within the measureable range of 0 to $50 \mu \varepsilon$ and $30^{\circ} \mathrm{C}$ to $80^{\circ} \mathrm{C}$ for strain and temperature, respectively. The easy fabrication method, high sensitivity, and good linearity would make this sensing device applicable in various applications such as health monitoring of spatial analysis of engineering structures. However, both minima $\left(\lambda_{1}\right.$ and $\left.\lambda_{2}\right)$ possess nearly identical sensitivities for both strain and temperature (i.e., $K \varepsilon$ and $K_{T}$ ). Consequently, very careful measurements are required for both of the measuring variables (strain and temperature) for simultaneous monitoring purposes, as a small measurement error in both minima $\left(\lambda_{1}\right.$ and $\left.\lambda_{2}\right)$ for both applied strain and temperature will be a cause for producing a significant error in the inversion calculations and hence will have a significant effect on the accuracy of the method. Authors are working to optimize the sensor's performance so that the sensor will be able to perform over a large measurement range with high sensitivity and precision.

Acknowledgments: The authors would like to thank the Universiti Teknologi Malaysia (UTM) for providing the facilities and funding for conducting this research. The authors are also grateful to the University of Malaya (UM) for providing the equipment for fabrication and measurements.

Author Contributions: The presented work was carried out in collaboration of all authors. H.H. Qazi, A.B. Mohammad and M.Z. Zulkifli conceived the idea and designed the experiments. H.H. Qazi and M.Z. Zulkifli performed the experiments. All authors analyzed the data, formulated the theoretical interpretation of the observed results. A.B. Mohammad and H. Ahmad provided the overall management of the project. Manuscript was written by H.H. Qazi and edited by A.B. Mohammad.

Conflicts of Interest: The authors declare no conflict of interest.

\section{References}

1. Harris, J.; Lu, P.; Larocque, H.; Xu, Y.; Chen, L.; Bao, X. Highly sensitive in-fiber interferometric refractometer with temperature and axial strain compensation. Opt. Express 2013, 21, 9996-10009. [CrossRef] [PubMed]

2. Gouveia, C.; Chesini, G.; Cordeiro, C.M.; Baptista, J.; Jorge, P.A. Simultaneous measurement of refractive index and temperature using multimode interference inside a high birefringence fiber loop mirror. Sens. Actuators B Chem. 2013, 177, 717-723. [CrossRef]

3. Kang, J.; Dong, X.; Zhu, Y.; Jin, S.; Zhuang, S. A fiber strain and vibration sensor based on high birefringence polarization maintaining fibers. Opt. Commun. 2014, 322, 105-108. [CrossRef]

4. Zhang, Y.; Huang, J.; Lan, X.; Yuan, L.; Xiao, H. Simultaneous measurement of temperature and pressure with cascaded extrinsic Fabry-Perot interferometer and intrinsic Fabry-Perot interferometer sensors. Opt. Eng. 2014, 53, 067101. [CrossRef]

5. Frazão, O.; Baptista, J.M.; Santos, J.L. Recent advances in high-birefringence fiber loop mirror sensors. Sensors 2007, 7, 2970-2983. [CrossRef]

6. Froggatt, M.E.; Gifford, D.K.; Kreger, S.T.; Wolfe, M.S.; Soller, B.J. Distributed strain and temperature discrimination in unaltered polarization maintaining fiber. In Optical Fiber Sensors; Optical Society of America: Cancun, Mexico, 2006.

7. Andre, R.M.; Marques, M.B.; Roy, P.; Frazao, O. Fiber loop mirror using a small core microstructured fiber for strain and temperature discrimination. IEEE Photon. Technol. Lett. 2010, 22, 1120-1122. [CrossRef]

8. Naeem, K.; Kim, B.H.; Kim, B.; Chung, Y. Simultaneous multi-parameter measurement using Sagnac loop hybrid interferometer based on a highly birefringent photonic crystal fiber with two asymmetric cores. Opt. Express 2015, 23, 3589-3601. [CrossRef] [PubMed]

9. Song, D.; Chai, Q.; Liu, Y.; Jiang, Y.; Zhang, J.; Sun, W.; Yuan, L.; Canning, J.; Peng, G.-D. A simultaneous strain and temperature sensing module based on FBG-in-SMS. Meas. Sci. Technol. 2014, 25, 55205-55210. [CrossRef]

10. Wolfbeis, O.S. Fiber Optic Chemical Sensors and Biosensors; CRC Press: Boca Raton, FL, USA, 1991.

11. Yin, S.S.; Ruffin, P. Fiber Optic Sensors; Wiley Online Library: Hoboken, NJ, USA, 2002. 
12. Qazi, H.H.; Mohammad, A.B.B.; Akram, M. Recent progress in optical chemical sensors. Sensors 2012, 12, 16522-16556. [CrossRef] [PubMed]

13. Bilro, L.; Alberto, N.J.; Sá, L.M.; Pinto, J.D.L.; Nogueira, R. Analytical analysis of side-polished plastic optical fiber as curvature and refractive index sensor. J. Lightwave Technol. 2011, 29, 864-870. [CrossRef]

14. Piliarik, M.; Homola, J.; Maníková, Z.; Čtyroký, J. Surface plasmon resonance sensor based on a single-mode polarization-maintaining optical fiber. Sens. Actuators B Chem. 2003, 90, 236-242. [CrossRef]

15. Lu, H.; Tian, Z.; Yu, H.; Yang, B.; Jing, G.; Liao, G.; Zhang, J.; Yu, J.; Tang, J.; Luo, Y.; et al. Optical fiber with nanostructured cladding of $\mathrm{TiO}_{2}$ nanoparticles self-assembled onto a side polished fiber and its temperature sensing. Opt. Express 2014, 22, 32502-32508. [CrossRef] [PubMed]

16. Slavík, R.; Homola, J.; Čtyroký, J.; Brynda, E. Novel spectral fiber optic sensor based on surface plasmon resonance. Sens. Actuators B Chem. 2001, 74, 106-111. [CrossRef]

17. Han, Y.; Chen, Z.; Cao, D.; Yu, J.; Li, H.; He, X.; Zhang, J.; Luo, Y.; Lu, H.; Tang, J.; et al. Side-polished fiber as a sensor for the determination of nematic liquid crystal orientation. Sens. Actuators B Chem. 2014, 19, 663-669. [CrossRef]

18. Tseng, S.-M.; Chen, C.-L. Side-polished fibers. Appl. Opt. 1992, 31, 3438-3447. [CrossRef] [PubMed]

19. South, I. Novel D-type fiber optic localized plasmon resonance sensor realized by femtosecond laser engraving. J. Laser Micro/Nanoeng. 2010, 5. [CrossRef]

20. Chen, C.H.; Tsao, T.C.; Tang, J.L.; Wu, W.T. A multi-D-shaped optical fiber for refractive index sensing. Sensors 2010, 10, 4794-4804. [CrossRef] [PubMed]

21. Chen, C.H.; Tang, J.L.; Wu, W. Novel Multi-D-Shape Fiber Optic Biosensor. In Proceedings of the 5th International Symposium on Machinery and Mechatronics for Agriculture and Biosystems Engineering, Fukuoka, Japan, 25-28 June 2010.

22. Cheng, S.-F.; Chau, L.-K. Colloidal gold-modified optical fiber for chemical and biochemical sensing. Anal. Chem. 2003, 75, 16-21. [CrossRef] [PubMed]

23. Chau, L.-K.; Lin, Y.-F.; Cheng, S.-F.; Lin, T.-J. Fiber-optic chemical and biochemical probes based on localized surface plasmon resonance. Sens. Actuators B Chem. 2006, 11, 100-105. [CrossRef]

24. Zhong, C.; Shen, C.; You, Y.; Chu, J.; Zou, X.; Dong, X.; Jin, Y.; Wang, J. A polarization-maintaining fiber loop mirror based sensor for liquid refractive index absolute measurement. Sens. Actuators B Chem. 2012, 16, 360-364. [CrossRef]

25. Feng, D. D-shaped plastic optical fiber sensor for testing refractive index. IEEE Sens. J. 2014, 14, $1673-1676$.

26. Jiang, L.; Zhao, L.; Wang, S.; Yang, J.; Xiao, H. Femtosecond laser fabricated all-optical fiber sensors with ultrahigh refractive index sensitivity: Modeling and experiment. Opt. Express 2011, 19, 17591-17598. [CrossRef] [PubMed]

27. Zhao, J.; Yin, G.; Liao, C.; Liu, S.; He, J.; Sun, B.; Wang, G.; Xu, X.; Wang, Y. Rough side-polished fiber with surface scratches for sensing applications. IEEE Photon. J. 2015, 73, 1-7. [CrossRef]

28. Kaminow, I.P. Polarization-maintaining fibers. Appl. Sci. Res. 1984, 41, 257-270. [CrossRef]

29. Grattan, K.T.V.; Meggitt, B.T. Optical Fiber Sensor Technology: Fundamentals; Springer: Heidelberg, Germany, 2000.

30. Shen, C.; Zhong, C.; Chu, J.; Zou, X.; Jin, Y.; Wang, J.; Dong, X.; Li, Y.; Wang, L. Temperature-insensitive strain sensor using a fiber loop mirror based on low-birefringence polarization-maintaining fibers. Opt. Commun. 2013, 28, 31-34. [CrossRef]

31. Frazão, O.; Marques, B.V.; Jorge, P.; Baptista, J.M.; Santos, J.L. High birefringence D-type fibre loop mirror used as refractometer. Sens. Actuators B Chem. 2008, 13, 108-111. [CrossRef]

32. Tan, Y.-N.; Zhang, Y.; Jin, L.; Guan, B.-O. Strain and temperature discrimination using concatenated fiber grating lasers. In Asia Pacific Optical Sensors Conference; International Society for Optics and Photonics: Bellingham, WA, USA, 2012.

33. Jiang, N.; Zhu, H.; Bao, K.; Hu, Y. Simultaneous discrimination of strain and temperature using dual-gratings in one fiber. Optik Int. J. Light Electron Opt. 2015, 126, 3974-3977. [CrossRef]

34. Wang, L.; Zhang, W.; Wang, B.; Chen, L.; Bai, Z.; Gao, S.; Li, J.; Liu, Y.; Zhang, L.; Zhou, Q. Simultaneous strain and temperature measurement by cascading few-mode fiber and single-mode fiber long-period fiber gratings. Appl. Opt. 2014, 53, 7045-7049. [CrossRef] [PubMed]

35. Li, C.; Ning, T.; Wen, X.; Li, J.; Zheng, J.; You, H.; Chen, H.; Zhang, C.; Jian, W. Strain and temperature discrimination using a fiber Bragg grating and multimode interference effects. Opt. Commun. 2015, 343, 6-9. [CrossRef] 
36. Gonzalez-Reyna, M.A.; Alvarado-Mendez, E.; Estudillo-Ayala, J.M.; Vargas-Rodriguez, E.; Sosa-Morales, M.E.; Sierra-Hernandez, J.M.; Jauregui-Vazquez, D.; Rojas-Laguna, R. Laser temperature sensor based on a fiber Bragg grating. IEEE Photonics Technol. Lett. 2015, 27, 1141-1144. [CrossRef]

37. Liu, H.B.; Liu, H.Y.; Peng, G.D.; Chu, P.L. Strain and temperature sensor using a combination of polymer and silica fibre Bragg gratings. Opt. Commun. 2003, 219, 139-142. [CrossRef]

38. Chen, H.F.; Wang, D.N.; Wang, Y. Simultaneous strain and temperature sensing using a slightly tapered optical fiber with an inner cavity. Analyst 2015, 140, 1859-1862. [CrossRef] [PubMed]

39. Han, Y.-G. Temperature-insensitive strain measurement using a birefringent interferometer based on a polarization-maintaining photonic crystal fiber. Appl. Phys. B 2009, 95, 383-387. [CrossRef]

40. Noh, T.-K.; Lee, Y.-W. Study on Dependence of Polarization-Maintaining Photonic Crystal Fiber-Based Polarimetric Strain Sensor on Sensing Fiber Length. J. Korean Inst. Illum. Electr. Install. Eng. 2013, 27, 1-6. [CrossRef]

(C) 2016 by the authors; licensee MDPI, Basel, Switzerland. This article is an open access article distributed under the terms and conditions of the Creative Commons Attribution (CC-BY) license (http://creativecommons.org/licenses/by/4.0/). 